\title{
POLÍTICAS PÚBLICAS E EDUCAÇÃO INCLUSIVA: POR UM DIÁLOGO POSSÍVEL
}

\author{
Herica Santos Molon ${ }^{1}$ \\ Erineia Martins Valadares Bittencourt ${ }^{2}$
}

\section{RESUMO}

Na última década, os debates acerca do fortalecimento da educação inclusiva tornaram-se mais fortes, tendo em vista à incessante luta dos movimentos sociais pela igualdade de direitos, o que resultou na promulgação de políticas públicas que têm como objetivo a garantia de direitos sociais, da equidade e uma educação de qualidade para todos. O discurso da inclusão escolar está na pauta do dia-a-dia de grande parte dos países, seja por questões raciais, de gênero, sexualidade, crença religiosa, seja por condições orgânicas, entre outras, tornando-se relevante um diálogo entre as políticas e as práticas em nosso país. Neste contexto, o presente artigo objetiva-se em apresentar algumas políticas públicas e refletir sobre a inclusão escolar como um meio de diminuição das desigualdades sociais. Vários avanços foram feitos em prol da educação inclusiva, contudo ainda existem inúmeras dificuldades para a efetiva concretização da inclusão escolar. Incluir todos na rede regular de ensino não basta, precisa de uma reorganização do espaço escolar e principalmente levar os professores a repensarem suas práticas cotidianas afim de promover uma educação voltada para a singularidade de cada indivíduo.

Palavras-chave: Diversidade. Educação Inclusiva. Políticas Públicas. Respeito.

\section{INTRODUÇÃO}

Mais do que possamos imaginar, as políticas públicas afetam as nossas vidas e as vidas de todos que nos cercam. Em um país do tamanho do nosso e a complexidade de desafios sociais e que ainda caminham lentamente em prol da transparência pública ideal, saber do significado e importância das políticas públicas é algo básico e essencial, a final de contas elas estão diretamente relacionadas com a questão dos planejamentos do setor público e a qualidade deste planejamento e sua efetivação está relacionada totalmente

\footnotetext{
${ }^{1}$ Mestranda do Curso em Ciências da Educação - hericasmolon@ hotmail.com

${ }^{2}$ Mestranda do Curso em Ciências da Educação - erineia.valadares@hotmail.com
} 
com a qualidade de nossa vida. As políticas Públicas atingem todos nós cidadãos, independente de grau de escolaridade, sexo, raça, religião ou nível social, também abrangem todas as áreas, como educação, saúde segurança, mobilidade, meio ambiente, habitação, dentre outros, ou seja, as políticas públicas são conjuntos de programas, ações, atividades discutidas, aprovadas e programadas pelo poder público (federal, estadual e municipal) que se desenvolvem diretamente ou indiretamente pelos entes públicos ou privados visando assegurar que todos os cidadãos possam ter vida digna.

A política pública é uma tentativa de intervenção para a redução de um problema público, ela é uma diretriz voltada para a resolução deum problema público. Não é apenas o governo que faz política pública, mas também a sociedade. É essencial que as políticas públicas sejam construídas pelas pessoas, pois dentro do processo da democracia, o direito não é apenas algo que é fornecido ele faz parte de um processo de construção e uma democracia cada vez mais participativa as políticas públicas devem ser construídas pela sociedade. É importante lembrarmos que as políticas públicas são a maneira que o estado, o governo efetiva ações em nome do bem público. É aquilo que a sociedade precisa e deseja ter e que o governo terá que fazer que aconteça para todos.

\section{Políticas públicas e Educação Inclusiva: educar para a diversidade.}

A educação inclusiva é um campo marcado por necessidades que devem ser examinadas sob diversas perspectivas, pois sua proposta inovadora implica um remanejamento e uma reestruturação radicais na dinâmica da escola. É necessário que as escolas se modifiquem para atender qualquer diversidade, para acomodar todas as crianças independente das suas condições social e cultural e suas características individuais. Ela é um assunto que gera muito debates, discursões e dúvidas acerca do que é mais adequado tanto para as crianças que possuem algum tipo de necessidade especial tanto para as crianças consideradas normais. A pessoa com deficiência é um ser humano que merece atenção e respeito, e que deveria ser aceita pela sociedade sem discriminação, mas a realidade mostra que as coisas são bem diferentes. Ainda existem muitas barreiras a serem quebradas para que os portadores de deficiências possam ser inclusas socialmente como cidadãs, com direitos e qualidade de vida. 
A grande barreira para a participação efetiva de pessoas com deficiência é a cultura. A humanidade carrega uma história de preconceito e discriminação sobre a deficiência que, segundo Sassaki (2003), começou praticando a exclusão social, em seguida o atendimento segregado dos princípios de integração ou normalização social, até adotar a atual filosofia da inclusão. De acordo com este autor (2006), esse processo de inclusão social "foi provocado pelo conceito de equiparação de oportunidades, elaborado, disseminado e defendido pelo movimento internacional em defesa dos direitos humanos [...]" Equiparação de oportunidades é "tornar acessíveis para qualquer pessoa todos os sistemas gerais da sociedade [...]”. (SASSAKI, 2006, p. 91)

O discurso de inclusão é necessário para que uma política excludente seja revista. E como incluir? Por se tratar de um demanda específica, a educação especial torna-se uma política focalizada, o que a constitui como prioridade em políticas públicas. Isso significa rever o papel da escola regular, pois as "políticas inclusivas supõem uma adequação efetiva ao conceito avançado de cidadania [...]" (Cury, 15 2005, p.12). Em face da legislação vigente, a escola é chamada e precisa estar preparada para universalizar o seu atendimento. No entanto, esse papel não corresponde somente a ela, no que diz respeito ao poder público, o item 66 da Declaração de Salamanca, indica que:

Políticos em todos os níveis, incluindo o nível da escola, deveriam regularmente reafirmar seu compromisso para com a inclusão e promover atitudes positivas entre as crianças, professores e público em geral, no que diz respeito aos que possuem necessidades educacionais especiais. (1994).

Mantoan afirma que "estar junto é se aglomerar com pessoas que não conhecemos. Inclusão é estar com, é interagir com o outro". Em entrevista à revista nova escola, quando questionada acerca do que é inclusão, afirmou que:

É a nossa capacidade de entender e reconhecer o outro e, assim, ter o privilégio de conviver e compartilhar com pessoas diferentes de nós. A educação inclusiva acolhe todas as pessoas, sem exceção. É para o estudante com deficiência física, para os que têm comprometimento mental, para os superdotados, para todas as minorias e para a criança que é discriminada por qualquer outro motivo. Costumo dizer que estar junto é se aglomerar no cinema, no ônibus e até na sala de aula com pessoas que não conhecemos. Já inclusão é estar com, é interagir com o outro. (REVISTA NOVA ESCOLA, 2005, p. 1)

Quando questionada sobre os benefícios que a inclusão traz para os alunos e professores, Mantoan enfatiza que:

A escola tem que ser o reflexo da vida do lado de fora. O grande ganho, para todos, é viver a experiência da diferença. Se os estudantes não passam por isso na infância, mais tarde terão muita dificuldade de vencer os preconceitos. A inclusão possibilita aos que são discriminados pela deficiência, pela classe social ou pela cor que, por direito, ocupem o seu espaço na sociedade. Se isso não ocorrer, essas pessoas serão sempre dependentes e terão uma vida cidadã pela metade. Você não pode ter um lugar no mundo sem considerar o do outro, valorizando o que ele é e o que ele pode 
ser. Além disso, para nós, professores, o maior ganho está em garantir a todos o direito à educação. (REVISTA NOVA ESCOLA, 2005, p. 1)

E ainda salienta que uma sociedade justa e que dê oportunidade para todos, sem qualquer tipo de discriminação, começa na escola.

A educação inclusiva constitui um paradigma educacional fundamentado na concepção de direitos, que conjuga igualdade e diferença como valores que não se separam, ou seja, são valores indissociáveis, e que avança em relação à ideia de equidade ao se comparado as históricas produções de exclusão dentro e fora da escola em tempos passados.

A inclusão de pessoas com deficiências na escola é um princípio de valorização do ser humano pelo que ele é, sem nenhum tipo de preconceito, para que elas possam exercer sua cidadania e se sentir integradas na sociedade, participando ativamente do processo de aprendizagem e das atividades educacionais propostas, contando com o apoio da escola, da equipe multidisciplinar, professores, família e comunidade.

O discurso de inclusão é necessário para que uma política excludente seja revista. Por se tratar de uma demanda específica, a educação especial (modalidade de ensino) torna-se uma política focalizada, o que a constitui como prioridade em políticas públicas educacionais.

Isso significa rever o papel da escola regular, pois as 'políticas inclusivas supõem uma adequação efetiva ao conceito avançado de cidadania [...]" (CURY, 2005, p. 12). Em face da legislação vigente, a escola é convocada e precisa estar preparada para universalizar o seu atendimento. Contudo, esse papel não corresponde somente a ela, no que diz respeito ao poder público, o item 66 da Declaração de Salamanca, indica que:

Políticos em todos os níveis, incluindo o nível da escola, deveriam regularmente reafirmar seu compromisso para com a inclusão e promover atitudes positivas entre as crianças, professores e público em geral, no que diz respeito aos que possuem necessidades educacionais especiais. (DECLARAÇÃO DE SALAMANCA, 1994, p. 15)

Sabemos que "a educação é uma entre várias práticas sociais institucionalizadas. Ela reflete as condições presentes na sociedade, o jogo de forças e o confronto de tendências e interesses." (LAPLANE, 2004, p.14). No caso da educação especial, a política e a legislação nacional atribuíram preferencialmente à escola regular a função de receber os alunos com necessidades educacionais especiais, mesmo ainda abrindo espaço ao atendimento dos alunos em classes especiais, escolas especiais, classes hospitalares ou núcleos especializados. 
Para não reduzir à escola a função de apenas "socializar" é necessário compreender qual a abrangência ou papel da educação especial e educação inclusiva (que também se remete ao debate sobre inclusão), pois apresentam também várias interpretações: ora em relação de oposição, ora de superação ou incorporação. Mrech esclarece que “[...] por educação inclusiva se entende o processo de inclusão dos portadores de necessidades educacionais especiais ou dos distúrbios de aprendizagem na rede comum de ensino em todos os seus níveis [...].” (MRECH, 1998, p. 37).

Entendemos inclusão pela máxima "Educação para Todos", mas devemos perceber que esse fenômeno não se refere apenas a educação e está intrinsecamente relacionado com outras políticas sociais, tais como distribuição de renda, acesso aos bens materiais, culturais e ao trabalho. $\mathrm{O}$ acesso a nossa herança cultural e à vida produtiva através também da educação é parte da construção da inclusão social e do exercício da cidadania.

Segundo a Lei № 10.172/2001, “a educação especial se destina às pessoas com necessidades especiais no campo da aprendizagem, originadas quer de deficiência física, sensorial, mental ou múltipla, quer de características como altas habilidades" (BRASIL, 2001, p. 55) A Educação Especial não perde significação ao atender de forma especializada, as crianças e adolescentes especiais. As Diretrizes Nacionais para Educação Especial na Educação Básica em seu art. 3o diz que:

\footnotetext{
Por educação especial, modalidade da educação escolar, entende-se um processo educacional definido por uma proposta pedagógica que assegure recursos e serviços educacionais especiais, organizados institucionalmente para apoiar, complementar, suplementar e, em alguns casos, substituir os serviços educacionais comuns, de modo a garantir a educação escolar e promover o desenvolvimento das potencialidades dos educandos que apresentam necessidades educacionais especiais, em todas as etapas e modalidades da educação básica.
}

Parágrafo único. Os sistemas de ensino devem constituir e fazer funcionar um setor responsável pela educação especial, dotado de recursos humanos, materiais e financeiros que viabilizem e deem sustentação ao processo de construção da educação inclusiva. (BRASIL, 2001, art. 3)

Portanto, uma sociedade inclusiva é aquela capaz de considerar as necessidades da condição humana, encontrando meios para que cada cidadão, do mais privilegiado ao mais comprometido, exerça o direito de contribuir com seu melhor para o bem comum.

Para garantir o direito de todos os alunos, independente da sua condição, de estarem juntos participando e aprendendo, sem ser discriminado, o Ministério da Educação apresenta a Política Nacional de Educação Especial na Perspectiva da Educação 
Inclusiva, que visa constituir políticas públicas promotoras de uma educação de qualidade para todos.

A Constituição Federal de 1988 tem como objetivos fundamentais "promover o bem de todos, sem preconceitos de origem, raça, sexo, cor, idade e quaisquer outras formas de discriminação" (art. $3^{\circ}$ Inciso IV). Como já mencionado anteriormente, o art. 205 preconiza que a educação como um direito de todos, garantindo o pleno desenvolvimento da pessoa, o exercício da cidadania e a qualificação para o trabalho. No seu art. 206, Inciso I, estabelece a "igualdade de condições de acesso e permanência na escola", como um dos princípios para o ensino e, garante como dever do Estado, a oferta do atendimento educacional especializado, preferencialmente na rede regular de ensino (BRASIL, 1988, art. 208).

O Plano Nacional de Educação-PNE aprovado pela Lei 10.172/2001 para vigorar entre os anos de 2001 a 2010, que destaca que "o grande avanço que a década da educação deveria produzir seria a construção de uma escola inclusiva que garanta o atendimento à diversidade humana." (BRASIL, 2001, p. 53)

O novo PNE foi aprovado em 2014, fixa em seu Art $2^{\circ}$, suas Diretrizes,

[...] I - erradicação do analfabetismo; II - universalização do atendimento escolar; IIIsuperação das desigualdades educacionais, com ênfase na promoção da cidadania e na erradicação de todas as formas de discriminação; IV- melhoria da qualidade da educação; V- formação para o trabalho e para a cidadania, com ênfase nos valores morais e éticos em que se fundamenta a sociedade; VI - promoção do princípio da gestão democrática da educação pública; VII - promoção humanística, científica, e cultural e tecnológica do País; VIII - estabelecimento de meta de aplicação de recursos públicos em educação como proporção do Produto Interno Bruto - PIB, que assegure atendimento às necessidades de expansão, com padrão de qualidade e equidade; IXvalorização dos (as) profissionais da educação; X-promoção dos princípios do respeito aos direito humanos, à diversidade e à sustentabilidade socioambiental] (BRASIL, 2014, p 1).

A Declaração de Salamanca (1994) foi um importante marco na luta em defesa da escola inclusiva e tem como objetivo o direito à educação, considerando as características dos alunos, com uma proposta de pedagogia centrada na criança e que respeite suas limitações e potencialidades. Mantoan (1997) defende que:

\footnotetext{
A inclusão institui a inserção de uma forma mais radical, completa e sistemática, uma vez que o objetivo é incluir um aluno ou grupo de alunos que não foram anteriormente excluídos. A meta da inclusão é, desde o início, não deixar ninguém de fora do sistema escolar, que terá de se adaptar às particularidades de todos os alunos. (MANTOAN, 1997, p. 8)
}

A Convenção Sobre os Direitos das Pessoas com Deficiência, aprovada ela ONU em 2006, da qual o Brasil é signatário, estabelece que os Estados Parte devam assegurar um sistema de educação inclusiva em todos os níveis de ensino, em ambientes que 
maximizem e desenvolvimento acadêmico e social compatível com a meta da inclusão plena defendida em seu artigo $5^{\circ}$.

1. Os Estados Partes reconhecem que todas as pessoas são iguais perante e sob a lei e que fazem jus, sem qualquer discriminação, a igual proteção e igual benefício da lei;

2. Os Estados Partes deverão proibir qualquer discriminação por motivo de deficiência e garantir às pessoas com deficiência igual e efetiva proteção legal contra a discriminação por qualquer motivo;

3. A fim de promover a igualdade e eliminar a discriminação, os Estados Partes deverão adotar todos os passos necessários para assegurar que a adaptação razoável seja provida;

4. Nos termos da presente Convenção, as medidas específicas que forem necessárias para acelerar ou alcançar a efetiva igualdade das pessoas com deficiência não deverão ser consideradas discriminatórias. (CONVENÇÃO SOBRE OS DIREITOS DAS PESSOAS COM DEFICIÊNCIA, 2006)

De acordo com a LDB nº 9394/96, os alunos têm direito: à educação, permanência na escola, respeito à diversidade e a pluralidade de culturas. Carvalho, Salermo e Araújo (Revista de Educação, 2015, p.34) ponderam que:

\footnotetext{
"As pessoas com deficiência alcançaram seus direitos de cidadãos, incluindo a educação na rede regular de ensino, conjuntamente com o restante da população, com conceitos e determinações impostos pela Legislação. Porém, na prática e realidade atuais, muitos obstáculos e incompreensões permanecem, dificultando a concretização da proposta da inclusão escolar. (REVISTA DE EDUCAÇÃO, 2015, p.34)
}

A lei garante educação para todos, mas na prática estamos longe de sermos uma sociedade inclusiva. Temos uma no passado uma história de exclusão e segregação das pessoas com deficiências. Frente a esse passado vergonhoso, a educação inclusiva objetiva o aprendizado de todos os alunos, permitindo a convivência e a integração social dos alunos com deficiência favorecendo a diversidade. Por meio dela, é possível educar crianças e jovens dentro do mesmo contexto escolar, concedendo a eles o pleno direito à escolarização.

A Educação Inclusiva é um movimento, sobretudo, social que compreende a educação como um direito humano e elemento formador de uma sociedade cidadã. É uma educação voltada para a formação completa e livre de preconceitos que reconhece as diferenças e dá a elas seu devido valor. Para que ela aconteça, é fundamental a criação de redes de apoio aos educadores. 
Mesmo garantida legalmente, inúmeras ainda têm sido as dificuldades para a concretização da inclusão escolar, como falta de estrutura física e tecnológica das escolas, a ausência de recursos pedagógicos adaptados, a precariedade do sistema de apoio especializado dentro das escolas regulares, insuficiência na capacitação de professores, além da baixa qualidade de ensino de muitos dos sistemas escolares públicos (BRASIL, 2008).

Carvalho, Salermo e Araújo (Revista de Educação, 2015, p.34) ressalta, contudo, que muitas das dificuldades em relação à inclusão educacional podem ser associadas não à dificuldade em trabalhar com uma condição de deficiência, mas às dificuldades de um sistema educacional, que persistem há décadas, sistema este que necessita transformar-se para superar os métodos tradicionais e adaptar-se à nova realidade social vivenciada.

\section{As demandas específicas da Educação Inclusiva no Brasil: desafios e perspectivas.}

O Art. $3^{\circ}$ da Lei 9.394 de 20 de dezembro de 1996 (Lei de Diretrizes e Bases da Educação Nacional), que diz que o ensino deve ser ministrado com: Igualdade de condições para o acesso e permanência na escola (Parágrafo I), valorização do profissional da educação escolar (Parágrafo VII) e garantia de padrão de qualidade (Parágrafo IX). O Art. $4^{\circ}$ da mesma Lei diz que o atendimento educacional especializado gratuito aos educandos com necessidades especiais, preferencialmente na rede regular de ensino (Parágrafo III) e acesso aos níveis mais elevados do ensino, da pesquisa e da criação artística, segundo a capacidade de cada um (parágrafo IV). Porém basta olhar para algumas escolas brasileiras que veremos a distância gritante entre a realidade e a proposta desses princípios e fins da educação nacional.

O movimento pela educação inclusiva não se restringe somente em incluir os alunos deficientes no ensino regular de ensino. Ele é um processo que amplia a participação de todos os estudantes dos grupos considerados excluídos, como por exemplo: negros, homossexuais, índios, etc., nos estabelecimentos regulares de ensino. Esse movimento visa o reconhecimento e a valorização das diferenças. A educação inclusiva discute a escola das diferenças e não a escola dos diferentes, pois uma coisa é dizer que a diferença está no outro. Outra coisa é dizer que a diferença está em cada um de nós, pois por excelência nós somos diferentes uns dos outros e essa diferença faz parte da condição humana e sua aceitação e reconhecimento leva à dignidade, a satisfação 
pessoal, o crescimento, a busca da convivência harmoniosa entre todas as pessoas na sociedade, e acima de tudo ao respeito que é o mínimo que temos que ter uns com os outros.

Ao incluir todos no sistema regular de ensino, há uma necessidade que a escola se organize e que haja uma reestruturação da cultura, da prática e das políticas adotadas pelas escola de modo que estas respondam à diversidade de alunos. Uma escola que pensa de modo inclusivo é uma escola que beneficia a humanidade. Para Sassaki:

\begin{abstract}
"Incluir é: um processo pelo qual a sociedade se adapta para poder incluir em seus sistemas sociais gerais pessoas com necessidades essenciais e, simultaneamente, estas se preparam para assumir seus papéis na sociedade (...) Incluir é trocar, entender, respeitar, valorizar, lutar contra a exclusão, transpor barreiras que a sociedade criou para as pessoas. É necessário oferecer o desenvolvimento da autonomia, por meio da colaboração de pensamentos e formulação de juízo de valor, de modo a poder decidir, por si mesmo, como agir nas diferentes circunstâncias da vida". (SASSAKI, 1997, p. 41)
\end{abstract}

Mesmo diante de numerosas campanhas, Leis, Decretos, discursos que cercam a educação especial e inclusiva, podemos afirmar que continuamos homogeneizando nosso comportamento e nossa concepção de ensino. Temos entranhados velhos paradigmas que nos remete ao preconceito em relação do que é diferente. Sabemos porém, que para haver a inclusão é preciso romper barreiras e ressignificarmos enquanto pessoas. Segundo Ferreira:

A inclusão envolve: [...] uma filosofia que valoriza a diversidade de força, habilidades e necessidades [do ser humano] como natural e desejável, trazendo para cada comunidade a oportunidade de responder de forma que conduza à aprendizagem e do crescimento da comunidade como um todo, e dando a cada membro desta comunidade um papel de valor. (FERREIRA, 2005, p. 44)

Neste sentido, percebe-se que o educador deve ser o mediador nesse processo de construção do conhecimento e da socialização do aluno. Educação inclusiva, portanto, significa educar todas as crianças em um mesmo contexto escolar. A opção por este tipo de Educação não significa negar as dificuldades dos estudantes. Pelo contrário. Segundo Daniela Alonso (2013) com a inclusão, as diferenças não são vistas como problemas, mas como diversidade. É essa variedade, a partir da realidade social, que pode ampliar a visão de mundo e desenvolver oportunidades de convivência a todas as crianças. Carvalho enfatiza:

Ao refletir sobre a abrangência do sentido e do significado do processo de Educação inclusiva, estamos considerando a diversidade de aprendizes e seu direito à equidade. Trata-se de equiparar oportunidades, garantindo-se a todos - inclusive às pessoas em situação de deficiência e aos de altas habilidades/superdotados, o direito de aprender 
a aprender, aprender a fazer, aprender a ser e aprender a conviver. (CARVALHO, 2005, p. 5)

Em artigo publicado em abril de 2012, na Folha de S. Paulo, o professor Rodrigo Hübner Mendes fala da importância da educação inclusive para todo o contexto da sociedade: "Além de ser um direito, a Educação inclusiva é uma resposta inteligente às demandas do mundo contemporâneo. Incentiva uma pedagogia não homogeneizadora e desenvolve competências interpessoais. A sala de aula deveria espelhar a diversidade humana, não escondê-la. Claro que isso gera novas tensões e conflitos, mas também estimula as habilidades morais para a convivência democrática. $\mathrm{O}$ resultado final, desfocado pela miopia de alguns, é uma Educação melhor para todos."

O professor e pesquisador português Luís de Miranda Correia, grande especialista no tema, em seu livro A Escola Contemporânea e a Inclusão de Alunos com NEE, argumenta: A inclusão permite um maior desenvolvimento acadêmico e social da criança, devido às interações estabelecidas. Prepara a criança para a vida na sociedade, pois quanto mais tempo a criança conviver com os outros, compreendendo as diferenças, melhor será a sua realização ao nível educacional, social e ocupacional.

Toda essa movimentação teórica e prática a favor da inclusão têm provocado um repensar do papel da educação, não apenas em nosso contexto, como em muitos países do mundo. Em consequência, toda prática que segregue indivíduos (seja em hospitais, asilos ou escolas especiais), ainda que com boas intenções, tem sido repensada e evitada. O seguinte trecho do Plano Nacional de Educação ilustra esse argumento aplicado à educação em nosso contexto:

\footnotetext{
Requer-se um esforço determinado das autoridades educacionais para valorizar a permanência dos alunos nas classes regulares, eliminando a nociva prática de encaminhamento para classes especiais daqueles que apresentam dificuldades comuns de aprendizagem, problemas de dispersão de atenção ou de disciplina. A esses deve ser dado maior apoio pedagógico nas suas próprias classes, e não separá-los como se precisassem de atendimento especial (PNE, 2000, p. 65).
}

Assim, em se tratando do atendimento às necessidades de todo e qualquer aluno, as atitudes de uma instituição educacional inclusiva enfatizam uma postura não só dos educadores, mas de todo o sistema educacional. Uma instituição educacional com orientação inclusiva é aquela que se preocupa com a modificação da estrutura, do funcionamento e da resposta educativa que se deve dar a todas as diferenças individuais, inclusive as associadas a alguma deficiência - em qualquer instituição de ensino, de qualquer nível educacional. As dificuldades encontradas nos ambientes escolares vão 
desde as péssimas condições das estruturas físicas das instituições, sabe-se que essas escolas foram construídas para uma sociedade cheia de barreiras de preconceitos o que dificulta fazer adaptações necessárias. A falta de formação dos professores também tem sido fator que dificulta a aprendizagem e adaptação das crianças com necessidades especiais nas escolas comuns, além do que são poucos os docentes que atuam nessa área da educação e muitos não querem trabalhar com crianças deficientes alguns por medo, receio, preconceito, baixo entusiasmo, baixos salários, além disso, os professores que estão na sala de aula não foram preparados para realizar esse tipo de atividade, o que os coloca em posição desconfortável e consequentemente prejudica o processo de inclusão escolar e de aprendizagem dos alunos, eles foram formados em um momento em que não havia esperança para essas pessoas, elas estavam às margens sociais. Silveira e Nascimento enfatizam que:

Segundo as diretrizes básicas traçadas pelo ministério de Educação- MEC, no Brasil, as alternativas utilizadas são: enriquecimento curricular e aceleração, ou as duas combinadas. Tanto uma quanto a outra devem estar de acordo com as características da escola e adequadas à realidade do aluno. (SILVEIRA E NASCIMENTO, 2011, p. 133)

Moreno acentua que:

Tanto a escola comum como a escola especial tem resistido às mudanças exigidas por uma abertura incondicional às diferenças. Uma das mais sérias e influentes razões para que essa situação se mantenha é a neutralização dos desafios que a inclusão impõe ao ensino comum e que mobilizam o professor a rever e a recriar suas práticas, a entender as novas possibilidades educativas trazidas pela escola para todas. Esses desafios estão sendo constantemente anulados, contemporizados por políticas educacionais, diretrizes, currículos, programas compensatórios (reforço, aceleração entre outros). Falsas saídas têm permitido às escolas comuns e especiais escaparem pela tangente e livrarem-se do enfrentamento necessário com a organização pedagógica. Entretanto, existem professoras dispostas a vencer barreiras como a falta de informação, o preconceito e a falta de formação, pois entendem que o papel do professor também é aprender e produzir seu próprio conhecimento. O professor precisa se abrir para o novo, pensar, produzir seu saber. A postura que os professores podem assumir frente ao novo, ao aprender, identifica diferentes modos de pensar a profissão, ela pode ser entendida como uma constante aprendizagem parte de um movimento permanente de busca. (MORENO, 2009, p. 4)

Nesse sentido, Freire coloca que "a consciência do mundo e a consciência de si como ser inacabado necessariamente inscrevem o ser consciente de sua inconclusão num permanente movimento de busca". (FREIRE, 1996, p. 64)

Silva e Freitas continuam enfatizando que: 
Acredita-se que a inclusão escolar passe por questões legais e didático-pedagógicas. Mas supõe-se, antes de tudo, que esta seja uma opção ideológica, a qual envolva valor, sentimento. Um professor muito bem formado didaticamente, que não tem uma atitude de respeito e valorização em relação às diferenças, à diversidade humana, não irá responder adequadamente a essa diferença. Alterações políticas, legais e administrativas em prol da inclusão social e escolar dos portadores de necessidades especiais vêm ocorrendo ao longo da história. A inclusão é um processo gradativo que leva tempo, é complexo, tem de ser construído aos poucos, sendo que a condição essencial para que esse processo ocorra baseia-se na mudança de postura perante a heterogeneidade humana, mediante a valorização da diversidade como um elemento enriquecedor do desenvolvimento pessoal e social. É necessário que um professor ou equipe escolar respeite as diferenças, que seja comprometido com elas, que acredite no potencial humano, acima de qualquer deficiência ou incapacidade, terá mais possibilidades de atender bem a essas diferenças. $\mathrm{O}$ importante, no processo de inclusão, é perceber que a diversidade não é um problema; pelo contrário, é perceber que é uma oportunidade de enriquecimento individual, social e de ensino/aprendizagem. A inclusão implica uma transformação considerável no espaço escolar. Implica quebrar e vencer paradigmas, buscar atender à diversidade humana com ajuda de recursos materiais, humanos e financeiros. O desafio é conseguir quebrar o esquema de homogeneidade. Espera-se que haja um empenho de toda a sociedade escolar para que, num futuro próximo, a diversidade deixe de ser um desafio para tornar-se uma conquista. Enfim, a inclusão não consiste apenas em inserir o aluno na classe e esperar que o professor aprenda a trabalhar com ele. Depende também da postura do profissional, das suas representações, de acreditar no potencial do aluno e no seu de aprender, de aceitar desafios, de criar o novo, assim como todo o sistema escolar, que necessita estar disposto e aberto a aceitar e incluir esses alunos. Inclusão escolar implica apostar em uma política educativa que assegure a atenção à diversidade como eixo central e que isso se verifique em todas as etapas educativas, para a vida toda. (SILVA E FREITAS, 2015, p. 7)

Estamos em uma luta diária para que a inclusão de fato aconteça em todos os campos de nossa sociedade, que os direitos de nossos semelhantes não sejam consciente ou inconscientemente, negados. Mantoan vislumbra a educação do futuro como:

[...] algo não acabado. [...] que ela sempre nos surpreenda e cada vez mais a educação consiga atender, mesmo que parcialmente, os reclames dos alunos, da nossa sociedade, mas sempre nessa ideia de que esses reclames tenham a ver com novidades, com formas realísticas de se viver no mundo. Portanto, espero o seguinte, não atingir qualquer meta, o que eu quero é fazer hoje o que é melhor par mim diante daquilo que é contingencial e circunstancial [...] (MANTOAN, 2017, p. 246)

Sabemos que a educação inclusiva, como prática em construção, está em fase de implementação. São muitos os desafios a serem enfrentados, mas as iniciativas e as alternativas realizadas pelos educadores são fundamentais. As experiências, agora, centralizam os esforços para além da convivência, para as possibilidades de participação e de aprendizagem efetiva de todos os alunos. Para Kant "o homem não pode tornar-se um verdadeiro homem senão pela educação. Ele é aquilo que a educação dele o faz". (KANT, 1996, p. 150) 


\section{CONSIDERAÇÕES FINAIS}

No decorrer desse trabalho analisamos as atuais políticas públicas voltadas para inclusão. Uma política pública precisa assegurar direitos de cidadania para todos os cidadãos ou de forma específica para uma comunidade, um segmento social, cultural, étnico ou econômico. A Constituição Brasileira assegura vários direitos a qualquer brasileiro que muitas vezes não são respeitados. Muitos desses direitos são reconhecidos pelo poder público e por parte da sociedade.

Atualmente a educação brasileira tem diante de si um grande desafio que é o de poder possibilitar o acesso e a permanência dos alunos com necessidades especiais nas escolas regulares.

Muito tem se pesquisado, leis estão sendo elaboradas, estamos na busca de uma sociedade inclusiva com uma educação inclusiva. Avanços vêm sendo feitos na construção e na efetivação de políticas inclusivas, mas o empenho dos órgãos governamentais e não - governamentais, podemos citar como exemplo a sociedade, precisa continuar e ser em ritmo acelerado, pois o que tem se visto é uma demanda crescente da população de necessita de um atendimento especializado e a políticas públicas caminhando vagarosamente.

A educação inclusiva é um campo marcado por necessidades de propostas inovadoras e de reestruturação das práticas pedagógicas escolares, no sentido de orientar e esclarecer educadores de como se posicionar diante do imenso desafio de adotar uma prática pedagógica que privilegie a diversidade na escola.

A pessoa com deficiência é um ser humano que merece atenção e respeito, e que deveria ser aceita pela sociedade sem discriminação, mas na realidade as coisas funcionam diferentes. Existem muitas barreiras que precisam ser ultrapassadas para que estas pessoas sejam inclusas socialmente como cidadãs, com direitos e qualidade de vida.

A Educação é um processo que se dá entre estado, família e sociedade. Todos devem estar envolvidos nesse processo para que de fato o desenvolvimento pleno do educando aconteça.

Atualmente a formulação de políticas públicas é entendida como coprodução entre estado e sociedade e essa participação da sociedade na formulação, acompanhamento e avaliação das políticas públicas é assegurada por lei. A Lei Complementar $n^{\circ} 131$ - Lei da Transparência (LEI COMPLEMENTAR No 131, 2009) estipula que todos os poderes 
públicos estão obrigados a assegurar a participação popular em sua gestão, ou seja, o que antes era só opção, passa a ser obrigação do estado e direito do cidadão.

A partir do que já foi construído, precisamos, juntos, expandir instrumentos e ações que viabilizem avanços na efetivação da educação como um direito inquestionável de todo e qualquer brasileiro, com ou sem deficiência. As diferenças humanas em sala de aula devem ser vistas como a força da escola, e não o contrário. Apenas assim, faremos da educação uma estratégia de desenvolvimento e combate à desigualdade em nosso país.

\section{REFERÊNCIAS}

BRASIL. Constituição da República Federativa do Brasil. Brasília: Senado Federal, 1988.

BRASIL. Declaração de Salamanca e linha de ação sobre necessidades educativas especiais. Brasília: UNESCO, 1994.

BRASIL. Declaração de Salamanca e linha de ação sobre necessidades educativas especiais. Brasília: UNESCO, 1994.

BRASIL. Lei de Diretrizes e Bases da Educação Nacional. Lei 9.394, de 20 de dezembro de 1996. Diário Oficial da União, Brasília, 2001.

BRASIL. Ministério da Educação. A Lei Complementar n 131 - Lei da Transparência (LEI COMPLEMENTAR Nº 131, 2009)

BRASIL. Ministério da Educação. Lei No 10.172, de 09 de janeiro de 2001. Aprova o Plano Nacional de Educação e dá outras providências.

BRASIL. Ministério da Educação. Lei No 13.005/ 2014. Plano Nacional de Educação.

BRASIL. Ministério da Educação. Secretaria de Educação Especial. Diretrizes Nacionais para a Educação Especial na Educação Básica. Secretaria de Educação Especial - MEC/SEESP, 2001.

BRASIL. Plano Nacional de Educação. Brasília, 2000.

CARVALHO, Camila Lopes de; SALERMO Marina Brasiliano; ARAÚJO Paulo Ferreira de. Horizontes - Revista de Educação, Dourados, MS, v.3, n.6, p. 34- 48, jul./dez. 2015

CARVALHO, Rosita Edler. Educação Inclusiva: com os pingos nos is. 3. ed. Porto Alegre: Mediação, 2005.

CURY. Carlos Roberto Jamil. Políticas inclusivas e compensatórias na Educação 
de educação inclusiva. Campinas-SP: Autores Associados, 2004.

FERREIRA, W. B. Educação inclusiva: será que sou a favor ou contra uma escola de qualidade para todos? BRASIL. MINISTÉRIO DA EDUCAÇÃO SECRETARIA DE EDUCAÇÃO ESPECIAL. INCLUSÃO - REVISTA DA EDUCAÇÃO ESPECIAL. ANO 1 - No 01 - OUTUBRO DE 2005, BRASÍLIA, DF FREIRE, M. O sentido dramático da aprendizagem. in.: GROSSI, E. P; BORDIN, J. (org.). Paixão de aprender. Petrópolis: Vozes, 1996.

Inclusão Escolar. In: GÓES, Maria Cecília Rafael de. Políticas e Práticas

Kant I. Sobre a Pedagogia. Trad Francisco Cock Fontanella. Piracicaba: Editora Unimep; 1996.

LAPLANE. Adriana Lia Friszman de. Notas para uma análise dos discursos sobre MANTOAN, Maria Teresa Eglér. EDUCAÇÃ̃ ESPECIAL E INCLUSÃO

ESCOLAR. Entrevista para Revista educação, arte e inclusão, volume, 13, nº 2, maio/agosto. 2017. ISSN 1984 - 3178. PAG 243.

MANTOAN, Maria Teresa Eglér. Inclusão escolar: o que é? por quê? como fazer? São Paulo: Moderna, 2006.

MEC/SEESP, n. 20, p. 37-39.

MRECH. L.M. O que é educação inclusiva? Revista Integração, Brasília, ORGANIZAÇÃO DAS NAÇÕES UNIDAS. Convenção sobre os Direitos das Pessoas com Deficiência, 2006.

SASSAKI, R. K. Vida Independente: história, movimento, liderança, conceito, filosofia e fundamentos. São Paulo: RNR, 2006.

SILVIEIRA, Tatiana dos Santos \& NASCIMENTO, Luciana Monteiro da. Educação Inclusiva. Caderno de Estudos. Indaial: UNIASSELVI, 2011. 